\title{
Mitigating Voltage Collapse in the Nigeria 44 Bus 330kV Power Transmission Network during Contingency of Three Phase Fault using ANN Controlled STATCOM.
}

\author{
E.N.Aneke*, I.I. Eneh ${ }^{* *}$, J.C.Iyidobi* ${ }^{* *}$ \\ *Electrical and Electronics Engineering Department, Enugu State University of Science and Technology, Agbani, Enugu PMB 01660 Nigeria \\ ${ }^{* *}$ Electrical and Electronics Engineering Department, Enugu State University of Science and Technology, Agbani, Enugu PMB 01660 Nigeria
}

DOI: 10.29322/IJSRP.11.09.2021.p11761

http://dx.doi.org/10.29322/IJSRP.11.09.2021.p11761

\begin{abstract}
This research is targeted at mitigating voltage collapse in the Nigeria 330KV 44-bus Network during contingency of three phase fault using artificial neural network (ANN) controlled Static Synchronous Compensator (STATCOM). Power system disturbances caused by faults, loss of generation, etc. lead to various forms of voltage instabilities. The effect of voltage instabilities in our Power system networks can be disastrous. This is because it can lead to loss of loads, loss of generation and loss of generator synchronism, under-voltage and ultimately, voltage collapse and blackouts. Models of the test network, STATCOM and its ANN controller were all developed in Simulink/Matlab. Transmission network data obtained from Transmission Company of Nigerian (TCN) Osogbo in addition to simulation data were used to train the ANN controller. A three-phase fault block was connected at Jos bus and was configured to introduce a three-phase fault into the network between 40s and 80s. The result and analysis of simulations revealed that ANN controlled STATCOM device mitigated voltage collapse in the Nigeria 330KV 44-bus power network during three phase condition by extending the point of voltage collapse mitigation margin of the network by a factor of 1.43 . it was concluded that ANN controlled STATCOM is effective in mitigating voltage collapse in a multi-bus network during contingency of three-phase fault.
\end{abstract}

Index Terms- Voltage Collapse; Voltage stability; STATCOM; ANN; PV Curve; PSAT; MATLAB/SIMULINK; Reactive Power.

\section{INTRODUCTION}

Multi bus power networks like the Nigeria transmission grid system is naturally vulnerable to faults and other contingencies. There are occasions where installed protection system of a network for one reason or the other fail to prevent or effectively resolve severe faults in complex power networks. Sustained severe three phase faults that are not properly handled by the network's protection system can introduce voltage instabilities which if not swiftly resolved could ultimately lead to voltage collapse and cascaded blackouts. Unfortunately, as electricity demand increases due to increase in population and commercial activities, most power networks are becoming more heavily loaded at a time when economic down turn is making it impossible to raise grid capacities (Niranjan etal 2016). This situation helps to put power grids under undue pressure and make them more prone to voltage collapse.

The Nigerian case is even more serious as the aged network has over time suffered from poor network infrastructure, inadequate maintenance, under generation and generally weak transmission and distribution capacities. These have made the Nigerian network even more vulnerable to faults and other contingencies that predispose a system to frequent instabilities and voltage collapse.

A voltage collapse of part or the entire 330KV grid network in Nigeria implies that millions of affected users will have to depend mainly on costly to run standby power sources to maintain their industries, commercial establishments and other domestic power needs. During such long outages, domestic users loose lots of perishable goods or spend much more to protect them by running standby generators. Similarly industrial and commercial users either shut down or run costly standby generators which eventually lower their productivity and increase their cost of production. The operators also loose vital equipment to the frequent disturbances caused by the outages. Due to the dynamic nature of power systems, constraints like switching actions, change in loads, faults etc, are commonly being imposed on power systems. These constraints put the power networks under stress and affect its behaviour (in terms of voltage profile, losses, stability and power transfer capability).

Since voltage collapse is caused by shortage of reactive power at network buses and which can be caused by line outage occasioned by faults; one way of minimizing voltage collapse in multi power networks is by installing reactive power compensators at strategic locations in the network. In this research work, Neural network controlled Static Synchronous Compensator (STATCOM) shall be used to replenish reactive power of the Nigeria 44 bus $330 \mathrm{kV}$ power grid network to prevent voltage collapse during contingency of three phase fault. STATCOM enhances voltage profile of network buses by providing adequate reactive power compensation at the 
vulnerable buses. Well trained neural network has proved to be very effective in controlling various FACTs devices for optimum performance.

\section{Voltage Collapse}

Voltage collapse, according to Kundur (1994) "is the process by which the system of events accompanying voltage instability leads to a blackout or abnormally low voltages in a significant part of the power system" (Kundur, 1994). It is possible for stable operation to continue at little voltage even after the transformer tap changers hit their maximum boost range; regardless of whether tripping of some of the loads is intentional or unintentional. As already stated, the principal factor that contributes to the instability of voltage is voltage reduction which occurs as a result of reactive and active power flowing across inductive reactance linked to a transmission system. This causes limitation in the voltage support and power transfer ability of that transmission network. Voltage support and power transfer are limited further whenever some generators reach their armature or maximum current time over-load capability range. The stability of voltage is considered vulnerable in any case where there is an increase in the demand of reactive power more than the maximum sustainability of the available resources of the reactive power as a result of disturbance in the system.

Basic phenomena linked with voltage stability/instability are:

i. Temporary load reduction

ii. Voltage in a specific area is reduced by a large (reactive) loading

iii. The area transfer capacity is reduced

iv. Recovery of load demand

v. Further reduction of voltage

vi. Voltage collapse becomes the case when load flow cannot be resolved.

\section{Causes of Voltage Collapse}

The endpoint of the series of events regarding instability of voltage might be a voltage collapse phenomenon. However, if this problem is detected earlier and countermeasures taken, the harmful effect of the said collapse can be reduced efficiently. Typical scenario leading to a power system voltage collapse can thus be summarized as follows:

When a transmission line is loaded heavily, it trips as a result of a fault and by implication causes more loading in the adjacent lines which are left. This typically results to increase in the requirement of the reactive power in lines since this requirement rises sharply for loads that are above the loading impedance surge.

\section{Voltage Collapse, System Change, and Reactive Power}

Voltage collapse usually exists in a faulty, heavily loaded system or a system that has a shortage of reactive power. When a transmission line is loaded heavily, it trips as a result of a fault and by implication causes more loading in the adjacent lines which are left. This typically results to increase in the requirement of the reactive power in lines since this requirement rises sharply for loads that are above the loading impedance surge. This event is actually the instability of a system which connects most components of the power system and their respective variables simultaneously. Voltage collapse regularly involves the power system as a whole, though relatively, the effect is felt more in a designated region of the power system than in the other regions. However, a good deal of other varying parameters is also fully involved. Critically analyzing the power system generation, reactive power generation, and the transmission of the system gives a clear insight regarding the nature of the voltage collapse. Hence voltage collapse is generally linked to the load power demands that are unable to be met due to restrictions in the reactive power transmission and generation. When there is a limitation in reactive power production including the generator, the reactive power limit or threshold of the Static Var Compensator (SVC), and decreased reactive power which are created at reduced voltages by capacitors.

Reactive power loss of a high magnitude in lines that are heavily loaded is the major problem in power transmission. Sequel to that is line outage possibility which in effect, causes reduction in the capacity of the transmission. The load reactive power demand is directly proportional to the load increase, changes in the composition of load, or the stalling of motors.

Other known changes in the power system that are responsible for voltage collapse include tripping of lines, load recovery dynamism, tap-changing actions of generators and transformers, outages of generators, and the event of the synchronous condensers hitting the limits of reactive power.

All the above-mentioned factors have a very noticeable effect on the production of reactive power, its transmission and its consumption.

For voltage stability problems to be investigated, the anatomy of reactive power should be understood (Okafor, 2007). When an electric current flow through a current-carrying wire (conductor), two natural phenomena are set up mainly; electric fields, and magnetic fields. Potential difference necessitates the electric field while current flow necessitates the establishment of magnetic field. These phenomena can be described by the Pointing vector $\mathbf{P}$, given by:-

$$
\mathbf{P}=\overline{\mathbf{E}} \times \mathbf{H} \mathbf{w} / \mathbf{m}^{2}
$$

The vector $\mathbf{P}$ defined by equation 2.1 above evidently has a direction perpendicular to the plane containing $\mathbf{E}$ and $\mathbf{H}$ and a magnitude $|\mathbf{P}|$ equal to $|\mathbf{E}||\mathbf{H}|$ sin $\boldsymbol{\delta}$, where $\boldsymbol{\delta}$ represents the angle between $\mathbf{E}$ and $\mathbf{H}$.

Equation (1) can be explained thus: - The electromagnetic energy travels in a direction coinciding with the direction of $\mathbf{P}$. The amount of energy that penetrates a unit area per unit time is given by the magnitude $|\mathbf{P}|$.

The electromagnetic field around the current-carrying conductors and between two conductors as a result of the electric voltage difference between them is shown in Figure 1. 


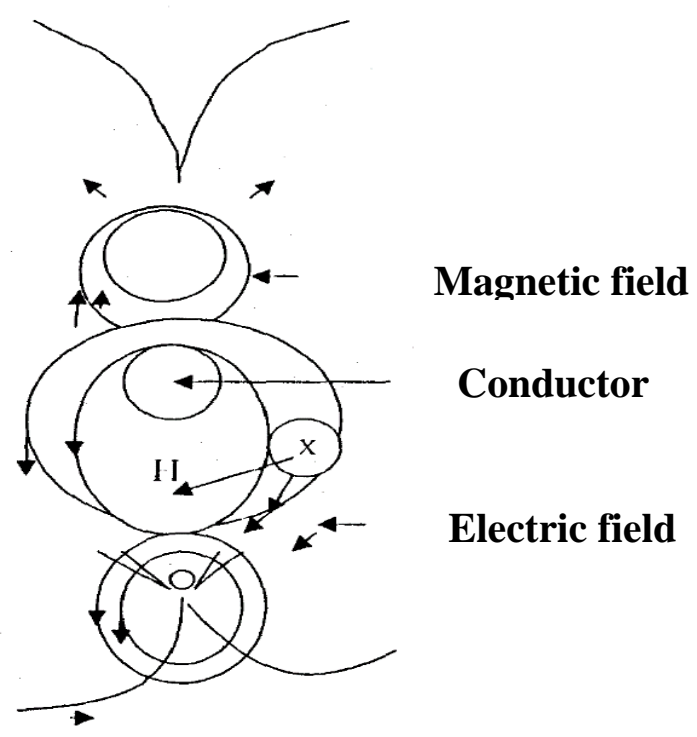

Figure 1: Electromagnetic field pattern around the current-carrying conductor

The total electromagnetic energy flow is obtained by integration over the total sectional area in figure 1 and if the necessary operations are performed.

$$
\mathrm{P}=\text { ei watts }
$$

Where $\mathrm{i}=\mathrm{I}_{\mathrm{m}} \sin \omega \mathrm{t}$ and $\mathrm{e}=\mathrm{V}_{\mathrm{m}} \sin (\omega \mathrm{t} \pm \phi)$ are the expressions for current and voltage respectively and the transmitted power would be

$$
\mathrm{ei}=\mathrm{V}_{\mathrm{m}} \mathrm{I}_{\mathrm{m}} \sin (\omega \mathrm{t} \pm \phi) \sin \omega \mathrm{t}
$$

Where $\omega$ is the angular velocity with its relationship to the frequency being $2 \pi \mathrm{f}$

Equation (3) may be written as:

From the rules of trigonometric functions; we have that this identity function:

$$
2 \operatorname{Sin} \mathrm{A} \operatorname{Sin} \mathrm{B}=\operatorname{Cos}(\mathrm{A}-\mathrm{B})-\operatorname{Cos}(\mathrm{A}+\mathrm{B})
$$

From (4),

$$
\operatorname{Sin} \mathrm{ASin} B=\frac{1}{2} \operatorname{Cos}(A-B)-\frac{1}{2} \operatorname{Cos}(A+B)
$$

Applying (5) on (3) yields:

$$
\mathrm{ei}=\mathrm{V}_{\mathrm{m}} \mathrm{I}_{\mathrm{m}}\left[\left(\frac{1}{2} \operatorname{Cos}(\omega t \pm \phi-\omega t)-\left(\frac{1}{2} \operatorname{Cos}(\omega t \pm \phi+\omega t)\right)\right]\right.
$$

Simplifying further yields:

$$
\text { ei }=\frac{1}{2} \operatorname{Vm} \operatorname{Im} \operatorname{Cos} \phi-\left(\frac{1}{2} \operatorname{Vm} \operatorname{Im} \operatorname{Cos}(2 \omega t \pm \phi)\right)
$$

When the root mean square (rms) values of current and voltage are introduced;

We have:

$$
\mathrm{S}=\mathrm{ei}=\mathrm{VICos} \phi-\mathrm{VICos}(2 \omega \mathrm{t} \pm \phi)
$$

This expression shows that part of the power oscillates at frequency $2 \omega$ about the mean square value.

By applying this trigonometric identity: $\operatorname{Cos}(\mathrm{A}+\mathrm{B})=\operatorname{Cos} \mathrm{ACos} B-\operatorname{Sin} \mathrm{ASinB}$, equation (7) can be further written as:

$$
\mathrm{S}=\mathrm{VI} \operatorname{Cos} \phi \text {-VI }(\operatorname{Cos} 2 \omega t \operatorname{Cos} \phi \pm \operatorname{Sin} 2 \omega t \operatorname{Sin} \phi)
$$

Simplifying (8) further yields:

Therefore,

$$
\mathrm{S}=\mathrm{VIC} \operatorname{Cos} \phi(1-\operatorname{Cos} 2 \omega t) \pm V I \operatorname{Sin} 2 \omega t \operatorname{Sin} \phi
$$

$$
\mathrm{S}=\mathrm{VI} \operatorname{Cos} \phi(1-\operatorname{Cos} 2 \omega t) \pm V I \operatorname{Sin} \phi \operatorname{Sin}(2 \omega t)
$$

This equation shows that alternating current flow can be decomposed into two parts. While the first part pulsates around anon negative average value, the second part has an average value of zero. The first term of equation (9) has a mean value of:

$\mathrm{P}=\mathrm{VICos} \phi$ and pulsates between zero and twice this value. This is termed the REAL OR ACTIVE POWER in watts.

The mean value of the second term in the equation is zero, while the amplitude of pulsation is $\mathrm{Q}=\mathrm{VISin} \phi$ and is also known as conserved or REACTIVE, and it is expressed in volt-amps.

Therefore, equation (9) can be improved and stated thus:

$$
\mathrm{S}=\mathrm{P}(1-\operatorname{Cos} 2 \omega t) \pm Q \operatorname{Sin}(2 \omega t)
$$

By examining equation (10), it can be seen that the electromagnetic field established in a conductor carrying current is associated with real and reactive power flows. 
This defined formula shows that

i. The real power is the average value of $\mathrm{S}$, it is the amount of transmitted useful power. The magnitude of this real power depends very much on the power factor $\operatorname{Cos} \phi$

ii. By definition, the reactive power is equivalent to the peak value of a power component that oscillates on the line, the resultant average value is zero, for this reason, it is not capable of any useful work.

For a stable and efficient power supply, both the real and reactive power balances, their energy balance as well, are desirable. The main difference between the real power balance and the reactive one is that the excess of reactive power in one part of the power system cannot always compensate for the same shortage of power in the other part. This is explained by the fact that long distance transmission of reactive power increases the power system losses leading to voltage collapse. Because these losses have to be reduced to the barest minimum to enhance voltage stability, the reactive flow control is very essential in power system operations.

\section{Static Synchronous Compensator (STATCOM)}

This device is the shunt element in the UPFC. It has found wide application in FACTS, and its main purpose is to support the working potential difference of the bus to which it is electrically installed and maintain stability of the dc-link capacitor voltage. This device is designed with a matching transformer with parallel connection orientation to the transmission line, an inherent commutated switching power converter and a DC link is shown below in figure 2.

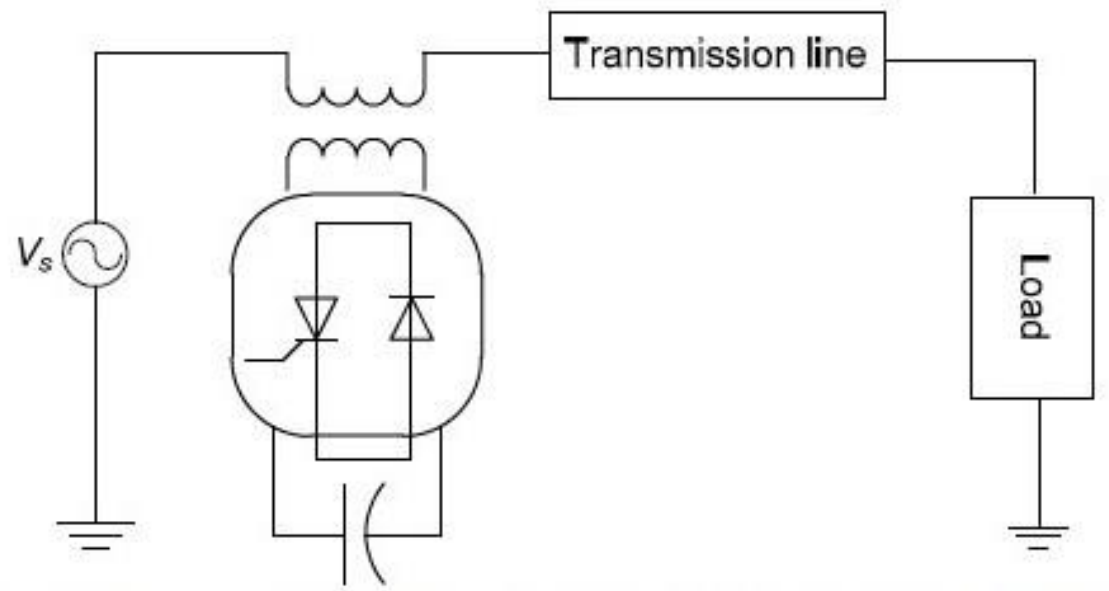

Figure 2: A STATCOM controlled two-bus network (Aneke et al,2021)

A DC input supplied to the circuit is converted to AC at the output. This controls the real power and as well the reactive power developed in the network. It also provides reactive power and controls active power flow, thereby enhancing the PTC of congested grid (Shakarami and Kazemi, 2010). In steady state analysis, the substitution of active power between the STATCOM and the transmission system can be neglected. Hence reactive only circulates between them (Zhang et al., 2004).

STATCOMs generally, do not need many reactive components in order to inject reactive power (either capacitive or inductive) to high voltage transmission network, unlike SVCs. One colossal advantage of these devices is that it requires smaller area and higher reactive power out at a low voltage transmission line since it acts an independent current source. More so, considering the dynamic stability, STATCOM affords a better suppressing behaviour than SVC since it can exchange active power with system transiently (Aneke etal, 2021).

\section{RESEARCH METHOD}

\section{Voltage stability and Collapse point determination Using PV Curve}

To assess the stability and collapse point of power systems, there are numerous derivations the indices of the bus/line stability are derived from solving the equation of the receiving end reactive and the receiving end active power line equation of the minimized two-bus equivalent network as proposed by Moghavvemi (1999).

Consequent developments engendered the advent of a popular equation of stability and collapse point index. This equation is a biquadratic equation which relates the receiving and sending ends of voltage magnitude and the power at a branch's receiving end. (Chakravorty, 2001; Avani, 2011).

Furthermore, when the discriminate of the given bi-quadratic expression which relates to any of the lines is zero, the critical or collapse point is said to be reached. Figure 3 shows a simple system. The system comprises of load which is fed through a reactance $\mathrm{X}$ by an infinite source. Equation 11 shows the complex receiving end power. 


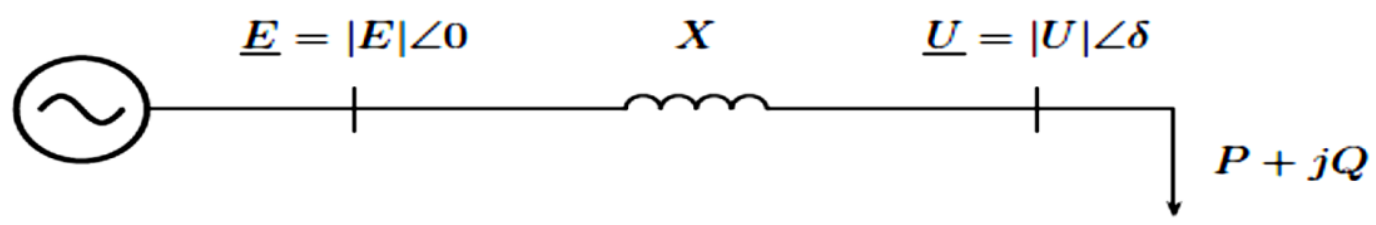

Figure 3: A Schematic diagram showingthe transmission system's aspects on voltage stabilit

Where:

$$
S=P+j Q=U * I=-\frac{|E||U|}{X} \sin (\delta)+j \frac{|E||U| \cos (\delta)-|U|^{2}}{X} \ldots \ldots \ldots
$$

$\mathrm{P}=$ active power

$\mathrm{Q}=$ reactive power

$\mathrm{U}=$ receiving end complex voltage $(U=|U| \angle \delta)$

$\mathrm{I}=$ complex current

$\mathrm{E}=$ Sending end complex voltage $(E=|E| \angle 0)$

The above equation can be broken down into two parts; P and $\mathrm{Q}$ to yield an equation of power flow thus:

$$
\begin{aligned}
& P=-\frac{|E||U|}{X} \sin (\delta) \\
& Q=\frac{|E||U| \cos (\delta)-|U|^{2}}{X}
\end{aligned}
$$

Eliminating $\delta$ from (2.13) above yields a second-order bi-quadratic equation as shown below:

$$
\left(|U|^{2}\right)^{2}+\left(2 Q X-|E|^{2}\right)|U|^{2}+X^{2}\left(P^{2}+Q^{2}\right)=0
$$

Solving for $U$ gives two solutions:

$$
|U|=\sqrt{\left(\frac{|E|}{2}-Q X \pm \sqrt{\frac{|E|^{4}}{4}-X^{2} P^{2}-X|E|^{2} Q}\right)}
$$

Equation (15) expresses the Power Voltage curve (Nose curve or PV). In the type of curve described by the equation, the voltage of the receiving end is dependent on the power of a given receiving end, thus providing a constant ratio which lies between the reactive and active power. The PV-curve shown in figures 4 and 5 are good examples. Figure 4 depicts the collapse margin. It should be observed that at the system's critical point which describes the very point of the collapse margin, discriminant of the equation (14) yields zero. This is shown in figure 5 as the $\mathrm{P}_{\max }$ point.

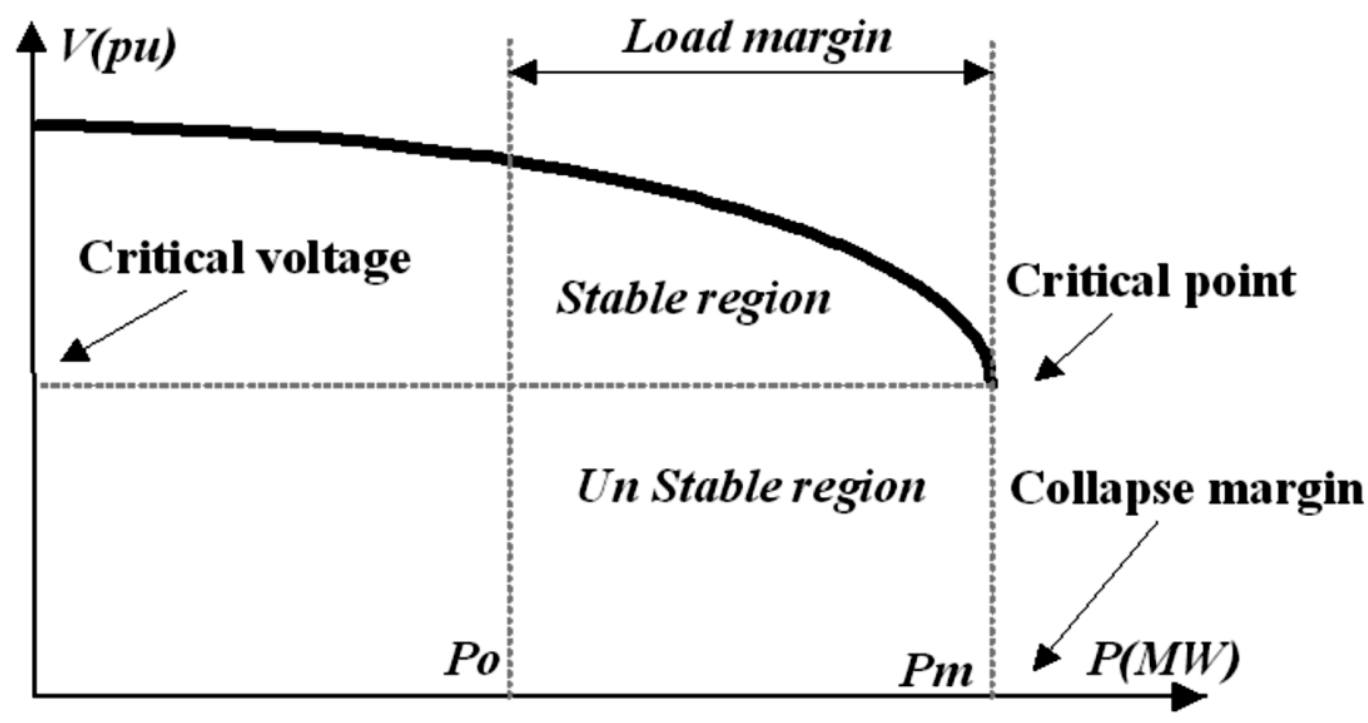

Figure 4: PV curve of the power system load bus system. Adopted from (Baalbergen, 2013) 


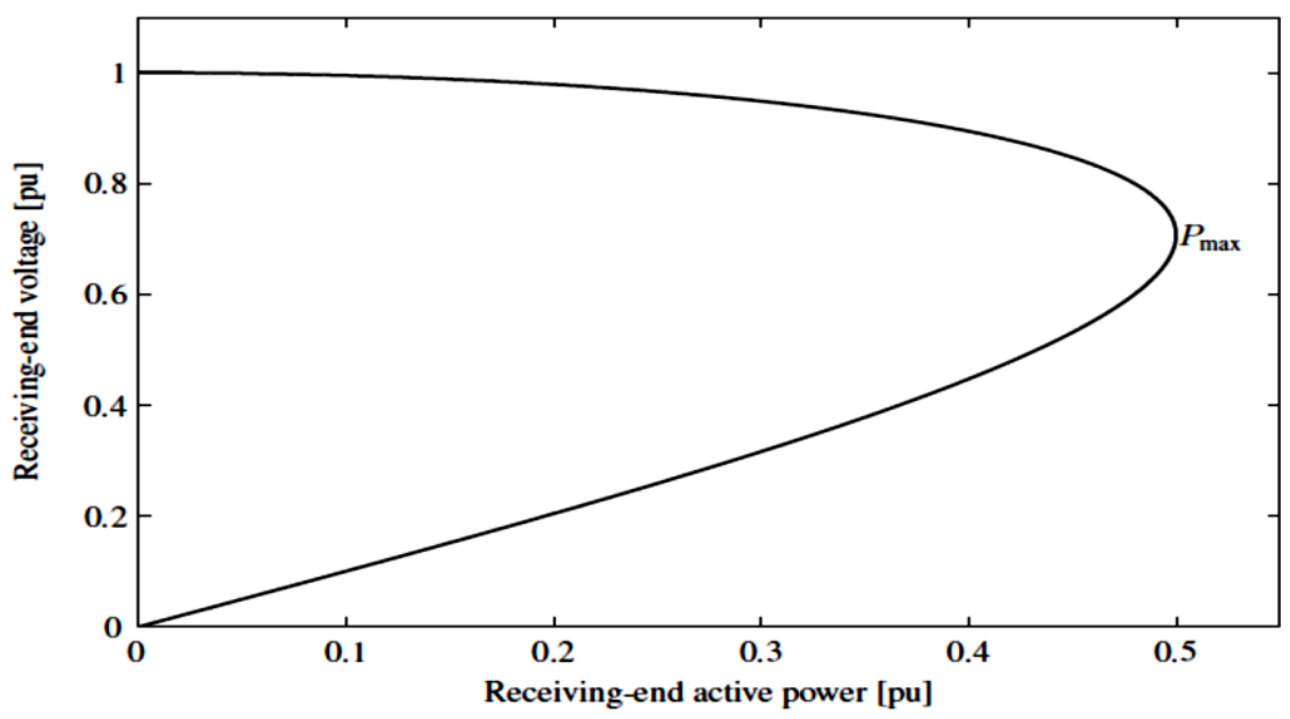

Figure 5: Generalized PV curve. Adopted from (Baalbergen, 2013)

Three different operation modes can be distinguished from the PV curve:

i. When $\mathrm{P}_{\text {load }}<\mathrm{P}_{\max }$ : The system operation in this instance is below the maximum power transfer point. Here, load power can possibly be supplied both at a lower and higher voltage level.

ii. When $\mathrm{P}_{\text {load }}=\mathrm{P}_{\max }$ : The system operation in this condition is at the highest power transfer point. The transfer of load power can only be done at a single voltage level.

iii. When $\mathrm{P}_{\text {load }}>\mathrm{P}_{\max }$ : This is a case whereby the equation of the power flow does not have any solution. This means that it does not have an operating point. When the required load power is higher than the $P_{\max }$, the system collapses due to absolute lack of equilibrium.

\section{Evaluation of Voltage Collapse Mitigation in The Test Network}

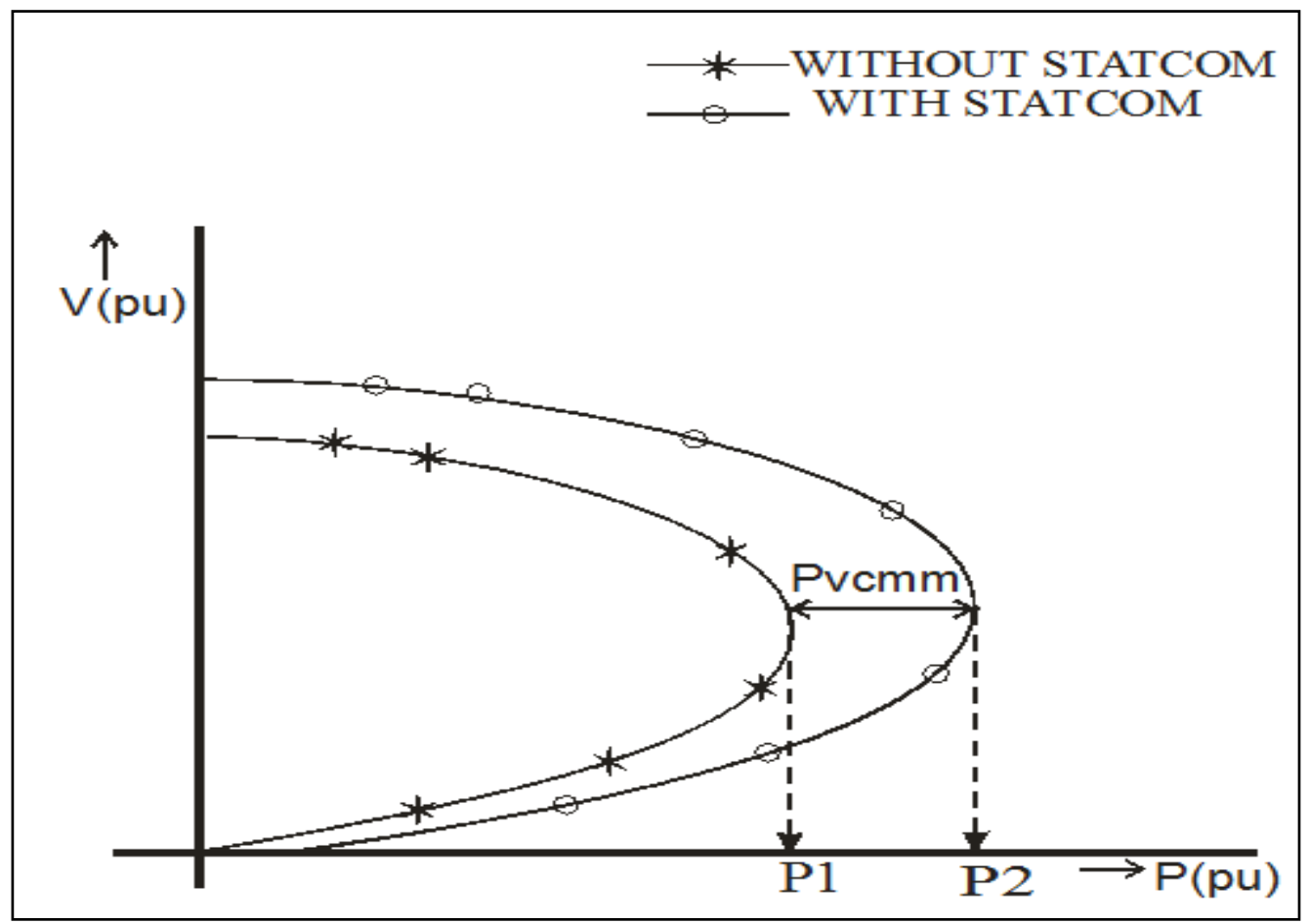

Figure 6: PV curve of weakest bus with and without STATCOM

In order to effectively evaluate the impact of ANN controlled STATCOM in mitigating voltage collapse in the Nigerian transmission grid power network (test network); a point of voltage collapse mitigation margin (PVCMM) index is defined thus: With reference to figure 6 , 
PVCCM Index $=\quad \frac{P 2-P 1}{P 1}$

Where;

$\mathrm{P}_{1}=$ maximum power transferred at voltage collapse point without STATCOM connected.

$\mathrm{P}_{2}=$ maximum power transferred at voltage collapse point with STATCOM connected

$\% \mathrm{PVCCM}=\frac{P 2-P 1}{P 1} \times \frac{100}{1}$

Where;

$\%$ PVCCM = Percentage Point of voltage collapse mitigation margin.

Three Phase Model of The Nigeria Transmission Grid Network

A reduced three phase network of the 44 bus $330 \mathrm{kV}$ Nigeria transmission network was used as the test network. A reduced version of the network was adopted to make the network less cumbersome and easier to work on. This was realized by modeling some sections of the network into an equivalent network. The equivalent network block in Matlab was used and helped to reduce the number of buses and other components in the network without changing the network's characteristics. There are two of such equivalent networks in the three phase system developed. The reduced three phase test network is shown in figure 7 (Aneke etal, 2021)

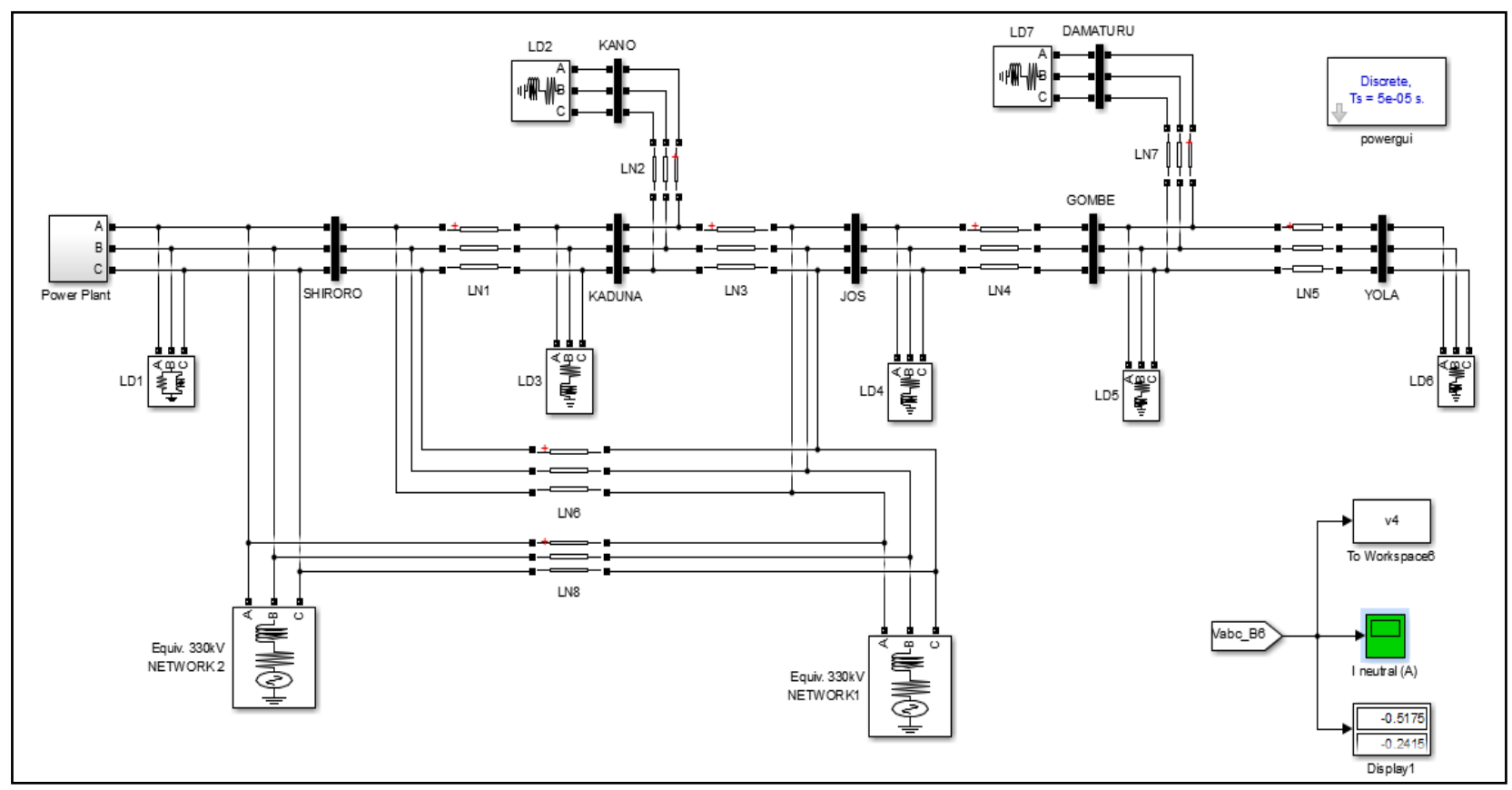

Figure 7: Reduced Version of the three Phase Simulink Model of the Nigerian 330kV Transmission Network.

\section{STATCOM Simulink Model}

The basic building block of the STATCOM is a Voltage Source Converter (VSC) and the device is shunt connected to the test network through a coupling inductance. The coupling inductance can be a transformer or a reactor if the device is designed for direct connection to the bus bars voltage level. In this work, the coupling inductance is a transformer. The STATCOM was modeled as an AC-voltage source to enable the magnitude, the phase angle and the frequency of the output voltage to be controllable.

To achieve this objective, a new model work space is created in Power System tool box (PSAT) Simulink environment. From PSAT library, the required component blocks (including transformer, voltage source converter, capacitor etc) are imported into the newly created work space. Each of the blocks is configured to reflect their ratings. At the end of the configuration, they are then linked together to form the STATCOM model.

Simulation is performed on the developed model to ensure that the model will perform as expected when connected to the test network. Simulating the STATCOM model is essentially to correct the error (s) that might pop up during the main simulation. Finally the model is saved to file for later use. The developed STATCOM MODEL is as shown below in figure 8. 


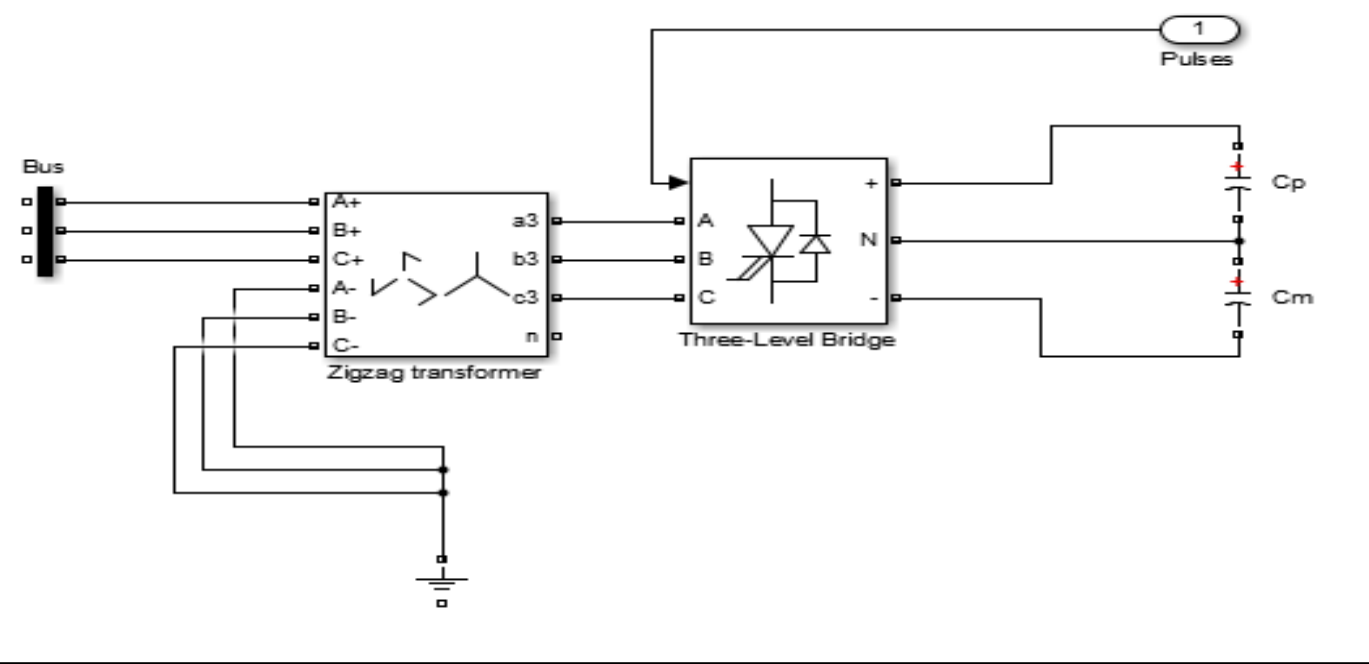

Figure 8: STATCOM Simulink model of STATCOM

\section{STATCOM Control Strategy}

The STATCOM is modeled as a voltage source inverter (VSI). Here the VSI converts direct current input voltage from the capacitor to AC output voltage supplied to the network bus. The output voltage supplied to the network bus helps to compensate active and reactive power demand at the bus where STATCOM is connected. Figure 9 shows the basic structure of ANN controlled STATCOM. The bus voltage and angle can be adjusted by controlling the injected real and reactive power at the AC network bus.

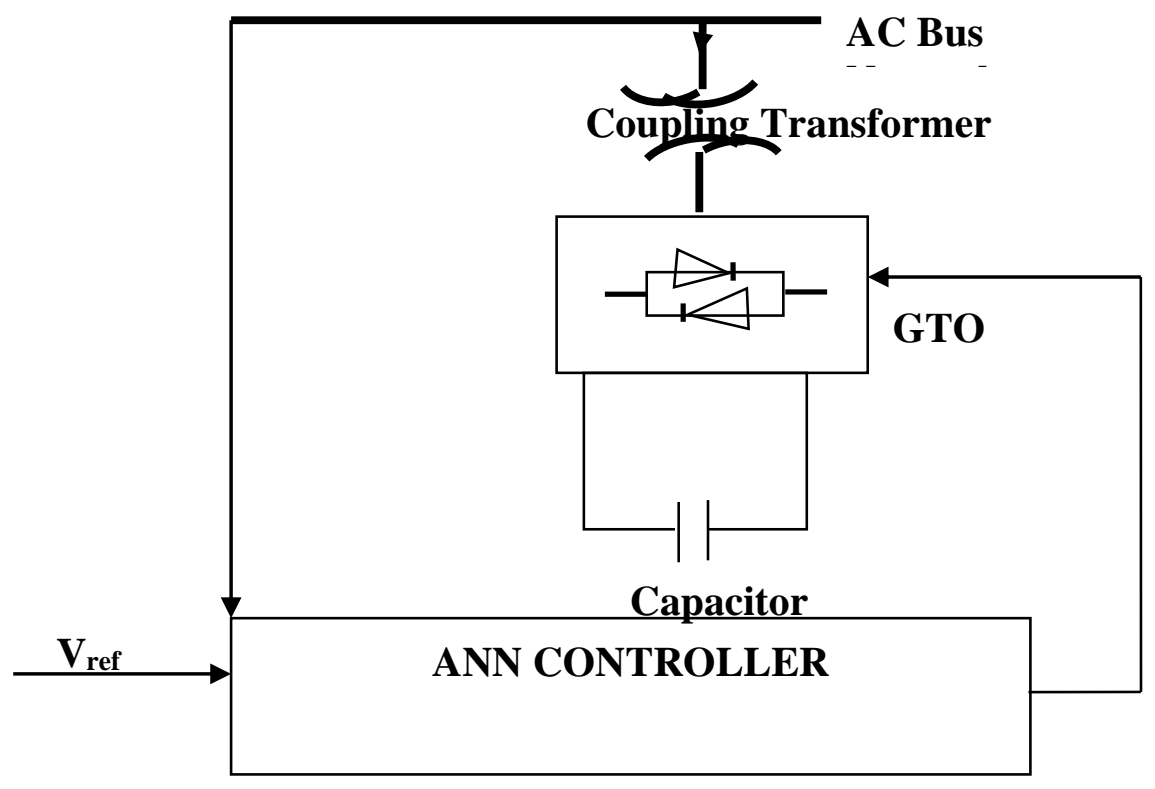

Figure 9: Structure of ANN Controlled STATCOM (Aneke et al,2021)

The control strategy applied here is to use a trained ANN controller to sense the AC voltage and compare it with the reference voltage and then adjust the voltage closer to the reference value. By doing this, the voltage stability of the network is enhanced and voltage collapse in the network mitigated.

By varying the value of the firing angles/pulses of the STATCOM bridges, STATCOM can enhance or reduce voltage profile of buses depending on the nature of compensation needed at the buses. The control action required by STATCOM to adjust the firing angles/pulses of its bridges so as to respond adequately to the challenges of the network is provided in this work by an ANN controller. To obtain the training data for the neural network, the three-phase test network will be simulated under normal working conditions to obtain optimum voltage profile values $(0.95$ to $1.05 \mathrm{pu})$, and under three phase fault situation to obtain bus voltage values below acceptable limit of 0.95 at the weakest bus with no STATCOM connected. STATCOM was then connected to the three-phase 
test network and simulated again. The firing pulses/angles of the STATCOM is then adjusted so as to keep the voltage profile of the weakest bus within acceptable range of $0.95 \mathrm{pu}$ to $1.05 \mathrm{pu}$ both during normal operation and during three phase fault condition. The voltage values obtained in the simulation without STATCOM and their corresponding firing angles/pulses in the simulation with STATCOM form the input and target training data respectively. The model of the ANN controller for the STATCOM was developed

\section{SIMULATION AND RESULTS}

The aim of this research work is show that an ANN controlled STATCOM can mitigate voltage collapse in the test network (Nigeria $330 \mathrm{KV}$ 44-bus network) during contingency of three phase fault by extending the voltage collapse margin of the network. To achieve this, a three-phase fault block was connected at Jos bus. The fault block was configured to introduce a three-phase fault into the network between $0.4 \mathrm{~s}$ and $0.8 \mathrm{~s}$. Figure 10 shows the test network connected to the ANN controlled STATCOM during a three-phase fault contingency condition. Figure 11 presents PV curves for three phase fault contingency case with and without STATCOM (With construction). The red line represents the PV curve during contingency of three phase curve but with ANN controlled STATCOM not connected. On the other hand, the blue line represents the PV curve during three phase fault situation but with ANN controlled STATCOM connected to the test network.

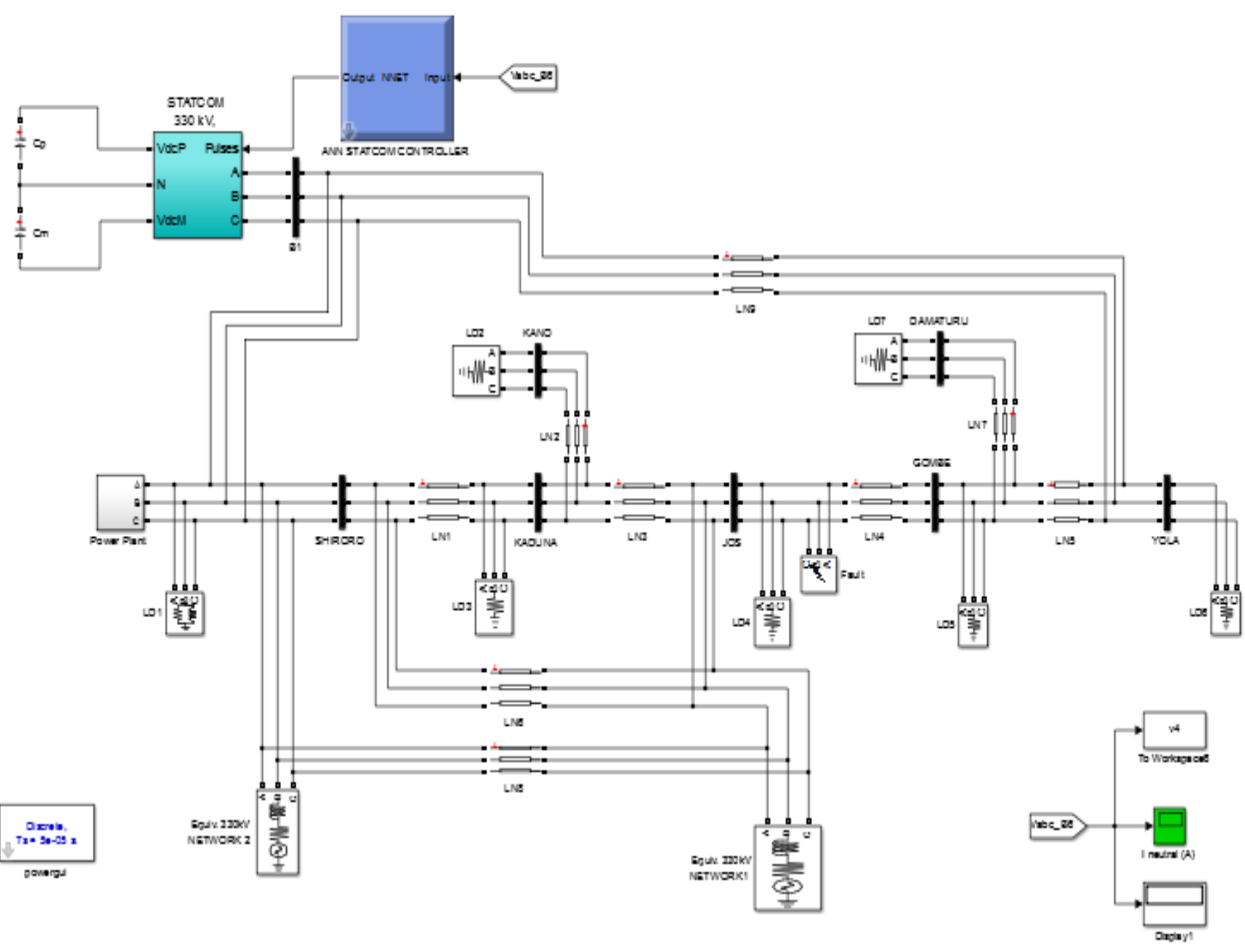

Figure 10: Three phase network of test system (for three-phase fault contingency) with STATCOM 


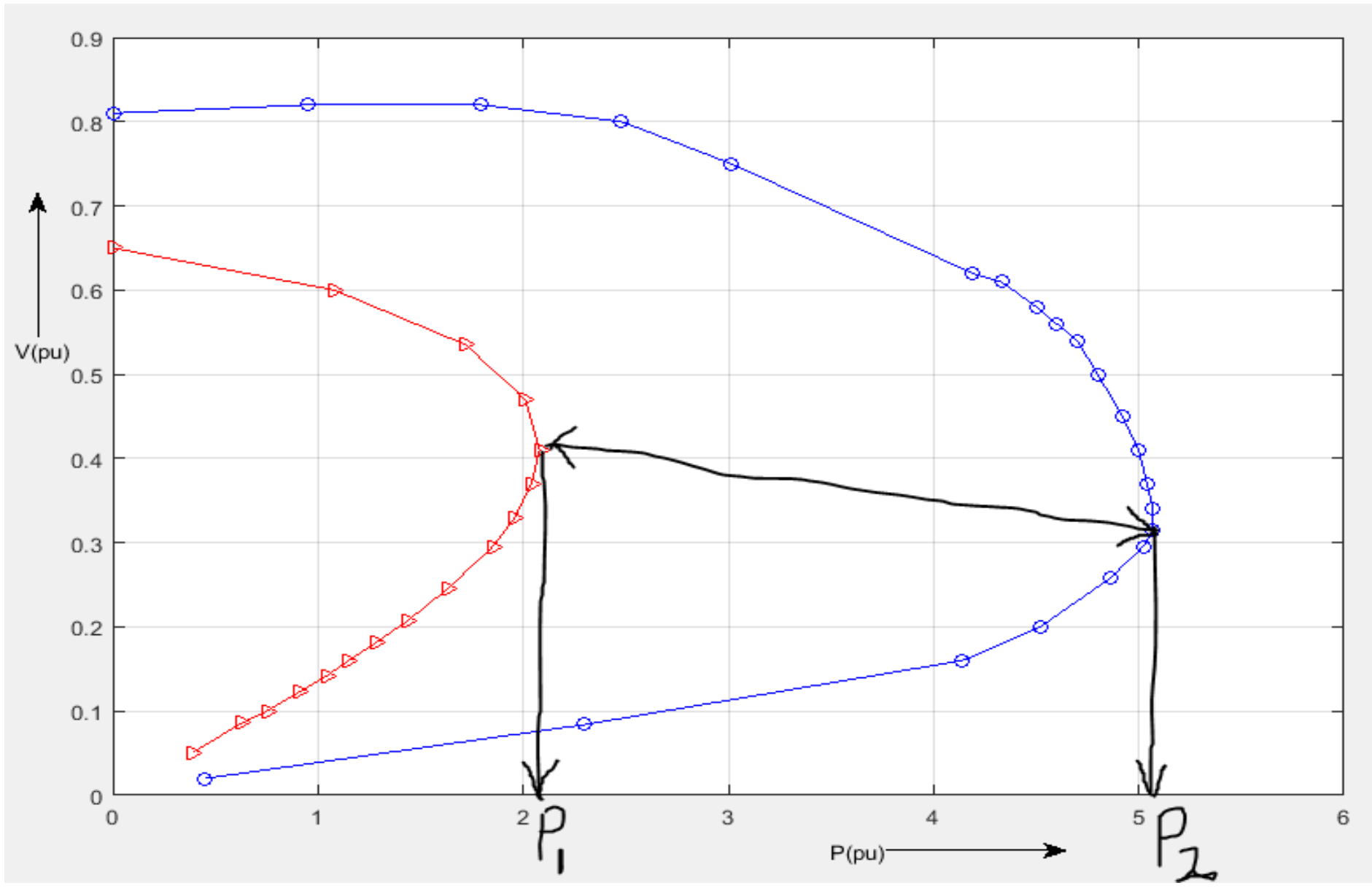

Figure 11: PV curves for three phase fault contingency case with and without STATCOM. (With construction)

From the PV curve of figure 11 and using equations (16) and (17), point of voltage collapse mitigation margin is computed thus:

$\mathrm{PVCMM}=(5.07-2.08) / 2.08$

$$
=1.437
$$

$\% \mathrm{PVCMM}=143.7 \%$

\section{ANALYSIS OF RESULT}

From the results obtained it can be seen that the connection of an ANN controlled STATCOM extended the point of voltage collapse by more than $143 \%$ relative to the point of voltage collapse when STATCOM was not connected. The implication of this extension is improvement on the loadability of the network by $143 \%$ before voltage collapse can occur. This is an appreciable level of voltage collapse mitigation in the test network. The result obtained also shows that the ANN controlled STATCOM is intelligent enough to stimulate enough reactive power support during severe contingencies

\section{CONCLUSION}

Voltage collapse is a consequence of sustained voltage instability on the Network due to faults or other network contingencies. Mitigating voltage collapse during fault conditions requires dynamic reactive/active power compensation on the network in question. In this research, voltage collapse was mitigated in the Nigeria 44 bus $330 \mathrm{KV}$ transmission network by Compensating the network with an ANN controlled Static Synchronous Compensator (STATCOM). The result of simulations carried out in this research work revealed that ANN controlled STATCOM device mitigated voltage collapse in the Nigeria $330 \mathrm{kV}$ transmission power network during three phase condition by extending the point of voltage collapse margin of the network by a factor of 1.43. 


\section{REFERENCES}

[1] Baalbergen J. F., (2013) “A project on Co-ordinated Agent-Based Control for On-line Voltage Stability Prevention", W"ohrmann Print Service, Zutphen, the Netherlands, 2013

[2] Chakravorty M., \&Das D., (2001) Voltage stability analysis of radial distribution networks, Electric Power and Energy System, Vol.23, pp.129-135.

[3] E.N.Aneke and E.N.C Okafor (2021). " Improving the Voltage Stability of the Nigeria 44 Bus 330KV Power Transmission Network using ANN Based Adaptive STATCOM Device" International Journal of Advanced Engineering Research and Science (IJAERS) [Vol-8, Issue-8, Aug- 2021], pp. 355-366

[4] Kundur P., (1994) "Power System Stability and Control". New-York: McGraw-Hill, 1994.

[5] Moghavvemi M., \&Faruque M. O., (1999) "Power system security and voltage collapse: a line outage-based indicator for prediction, Electric Power and Energy System", Vol.21, pp.455-461.

[6] Okafor,E. N. C. (2007). "Voltage Stability Evaluation for System Collapse Improvement in Nigeria Electric Power System using Modal Technique". PhD Thesis, Department of Electrical and Electronic Engineering, Federal University of Technology Owerri, 174p.

[7] Shakarami, M.R., Kazemi, A., 2010. "Robust design of static synchronous series compensator-based stabilizer for damping inter-area oscillations using quadratic mathematical programming". J. Zhejiang Univ.-Sci. C (Comput.\& Electron.), 11(4):296-306. [doi:10.1631/jzus.C0910428]

[8] E.N.Aneke, B.E Ibekwe, Iyidobi J.C., and and E.N.C Okafor (2021). "Voltage Stability Evaluation In The Nigeria 44 Bus Grid Network Using Modal Analysis." Journal of Engineering Research and Reports Volume 20 Issue 11 Pages PP 80-86

[9] Ibekwe B.E \& Aneke E.N (2020) "AC to DC Converter Power Factor Correction Using Current Controlled Pulse Width Modulation (C.C.P.W.M) Techniques" International Journal of Scientific \& Engineering Research Volume 11, Issue 12, December-2020 492

[10] Aneke N.E \& Ngang N.B (2021) Improving the Efficacy of the Nigerian Electric Power Transmission Network Using Static Synchronous Compensator (STATCOM) Journal of Information Engineering and Applications ISSN 2224-5782 (print) ISSN 2225-0506 (online) Vol.11, No.2, 2021

[11] Ezekiel Aneke \& Engla Anzaku (2019). Enhancing the Voltage Stability of the Nigerian 330KV 48-Bus Power System Network Using Modal/Eigenvalue Analysis. Journal of Information Engineering and Applications ISSN 2224-5782 (print) ISSN 2225-0506 (online) Vol.9, No.7, 2019

[12] Aneke, E. N. (2021). "Voltage Stability Evaluation for System Collapse Mitigation in Nigeria Electric Power 330kV Network using Modal Technique and Static Synchronous Compensator Device". PhD Thesis, Department of Electrical and Electronic Engineering Enugu State University of Science and Technology, Agbani, Enugu, 183p.(Unpublished)

\section{AUTHORS}

First Author - E.N. Aneke, B.Eng,M.Eng,Ph.D, Enugu State University of Science and Technology, Agbani, Enugu PMB 01660 Nigeria.

Second Author - Professor I.I. Eneh, B,Eng,M.Eng,Ph.D, Enugu State University of Science and Technology, Agbani, Enugu PMB 01660 Nigeria. Third Author - Dr.J.C. Iyidobi, B.Eng,M.Eng,Ph.D, Enugu State University of Science and Technology, Agbani, Enugu PMB 01660 Nigeria.

Correspondence Author - Ezekiel Nnamere Aneke, Email: ENG.Ezekiel.Aneke@ieee.org, aneke.ezekiel@gmail.com, +238153109956. 